\title{
Is there transparency in the pricing of medicines in the South African private sector?
}

\author{
V Bangalee, ${ }^{1}$ BPharm, MPharm, PhD; F Suleman, ${ }^{1,2}$ BPharm, MPharm, PhD \\ ${ }^{1}$ Discipline of Pharmaceutical Sciences, School of Health Sciences, Westville Campus, University of KwaZulu-Natal, Durban, South Africa \\ ${ }^{2}$ Prince Claus Chair of Development and Equity for the theme Affordable (Bio)Therapeutics for Public Health (September 2016 - September 2018), \\ Faculty of Sciences, Utrecht University, Utrecht, The Netherlands
}

Corresponding author: V Bangalee (bangalee@ukzn.ac.za)

Recent investigations by the Competition Commission of South Africa (SA) of suspected excessive pricing of cancer medicines in SA by three global pharmaceutical companies have once again drawn attention to increasing medicine pricing transparency and warrant further public debate.

S Afr Med J 2018;108(2):82-83. DOI:10.7196/SAMJ.2018.v108i2.12815

Recent investigations by the Competition Commission of South Africa (SA) of suspected excessive pricing of cancer medicines in South Africa (SA) by three global pharmaceutical companies, i.e. Roche Holding AG (Roche), Pfizer Inc. (Pfizer) and Aspen Pharmacare Holdings Ltd (Aspen), have once again drawn attention to the need for medicine pricing transparency. These companies have been accused of engaging in excessive pricing, price discrimination and/or exclusionary conduct in the provision of breast cancer medicine in SA. ${ }^{[1]}$

Previously, in the SA private sector, medicine price inflation, medicine price transparency and medicine price uniformity represented significant problems in an unregulated medicines market. ${ }^{[2]}$ The loss of benefits to consumers resulting from the high levels of discounting and payment of incentives within the pharmaceuticals supply chain had raised serious concerns in the National Department of Health and made it difficult to determine the true price of a medicine. ${ }^{[3]}$ The single exit price (SEP) regulation, first introduced in 2004 for all medicines in the private sector, is an example of SA's attempt to control prices and improve pricing transparency in the supply chain. The SEP, which is a composite of the ex-manufacturer's price, logistics fee and value added tax (VAT), standardised in SA at $14 \%$, mandated that manufacturers sell their products at one price to all their customers (other than the State), regardless of the nature of the customer's order size and consumption levels. ${ }^{[4,5]}$ Under this regulation, manufacturers were allowed to set their SEP at the time of introduction of the product, which may be raised once on an annual basis. They may, however, make several temporary price reductions during the year for competitive reasons. ${ }^{[6]}$

However, over a decade since its introduction as a price-control measure for medicines, complaints about access to affordable medicines in SA still persist. After the initial cost reduction brought about by the SEP, there has not been any formal adjudication of prices against comparable products in SA. Prices remain artificially inflated compared with the same products available internationally, ${ }^{[7]}$ as is the premise for the case against Pfizer, which is being investigated for excessive pricing of the lung cancer medication Xalkori (crizotinib) in SA. ${ }^{[1]}$ Similarly, Aspen, which is the dominant firm in the provision of Leukeran (chlorambucil), Alkeran (melphalan) and Myleran (busulfan) in SA, has seemingly taken advantage of their monopoly in the market and are under investigation for excessive pricing of these medicines. ${ }^{[1]}$ After observing that medicine prices and out-of-pocket spending on medicines were increasing, consumer advocates and policy makers have called for greater price transparency. ${ }^{[8]}$ Several factors have been recognised that constitute reduced transparency in the supply chain.

Among these is a lack of transparency in determining the logistics fee segment of the SEP. The logistics fee is determined through negotiations between the manufacturer or importer and the logistics service provider; however, the process and contracts are not made public. Manufacturers pay wholesalers and distributors a logistics fee from the SEP, but it is not evident if all logistics service providers are able to negotiate the same fee or if the fee is as reflected in the medicines database (South African Medicine Price Registry). ${ }^{[9]}$ The nature of these negotiations, which include concealment by manufacturers of prices or a price-setting approach, represents a barrier to price transparency in the SEP ${ }^{[10]}$ The allegation by stakeholders, such as Transpharm, that the logistics fee is being exploited by pharmaceutical companies, led to the following proposals. ${ }^{[1]}$ Firstly, transparency in the logistics fee is required by Regulation 21(2)(d) of the Medicines and Related Substances Act, 1965 (Act No. 101 of 1965), as amended. Secondly, Regulation 5(2)(f) states that the manufacturer and logistics provider must agree on a fee; and, thirdly, that under Regulation 5(2)(g) there be a cap on the logistics fee (as opposed to a fixed fee). ${ }^{[11]}$

In addition to the logistics fee, SA's current patent laws further contribute to artificially inflated prices. As argued by some parties, pharmaceutical manufacturers have a broad discretion in determining the prices they charge, and patent protection provides a source of monopoly that allows manufacturers a higher profit than the marginal cost of production. ${ }^{[7]}$ 'Ever-greening' of products also remains a significant issue, as manufacturers prolong their patents through marginal adaptations to product formulations. In most instances, these adaptations do not offer any clinically significant advantages to patients - the more pertinent consequence being the barrier to generic medicine entry for many years beyond the original patent. This limits medicine accessibility and artificially sustains the inflated cost of a medicine. ${ }^{[7]}$ Roche has been suspected of using the ever-greening strategy for its breast cancer medicines (Herceptin 
(trastuzumab) and Herclon (trastuzumab)) to the detriment of patients and in contravention of the Competition Act. ${ }^{[1]}$

Under the current SEP regulation, companies of originator medicines still have the freedom to set launch prices. However, the Pricing Committee is responsible for determining annual price increases in accordance with the SEP regulation methodology. Consequently, pricing of these medicines remains largely at the discretion of the manufacturer. In this regard, government has proposed the introduction of an international benchmarking system, in which the prices of originator medicines will be compared with those in a basket of countries (Australia, Canada, New Zealand and Spain, together with SA). For generic medicines, the ex-manufacturer price is to be set at least $40 \%$ lower than the existing price of the originator medicine. ${ }^{[12]}$ The process is likely to reduce the SEP of medicines in SA and create some transparency of pricing at the ex-manufacturer level. This legislative framework has been in the pipeline since 2006, but has faced stiff lobbies in terms of implementation. If implemented, it would reduce originator medicine costs by $\sim 25 \% .{ }^{[13]}$ In addition to international benchmarking, the application of pharmacoeconomics analyses on a voluntary basis has also been proposed to determine medicine prices. This provision, however, requires considerable resources and capacity on the part of the manufacturers to prepare submissions, as well as by the Pricing Committee to critically assess the submissions and make defensible determinations on that basis. ${ }^{[9]}$

Arguments against increased transparency of negotiations and publication of detailed individualised pricing data derive mainly from manufacturers, as it carries the risk of allowing competitors to be aware of other manufacturers' pricing strategies and therefore exposes companies to antitrust liability. Antitrust laws prohibit activities that restrict competition. This exchange of commercially sensitive information between competitors may facilitate price co-ordination and result in standardisation of prices. Thus, any system aimed at increasing price transparency should always be cautionary of antitrust rules and try to simultaneously establish a fair price for medicines. ${ }^{[14]}$

It is also vital that there is greater transparency and consistency in the pricing of medicines across the SA public and private healthcare sectors. The economic objectives of the National Drug Policy have been to attain affordable prices for all SA citizens, but there are irregularities and discrepancies in medicine pricing across the two sectors. Price variations exist because public, private and nongovernmental sectors procure medicines separately. Comparative state tender prices have revealed that some medicines are available to the state at approximately one-tenth of the cost of the same medicine in the private sector. ${ }^{[7]}$ Roche has been implicated in price discrimination by charging differential prices for breast cancer medicines in the private and public healthcare sectors by restricting the sale of Herceptin and Herclon to a particular sector. ${ }^{[1]}$ It has been estimated that a 12-month course of Herceptin costs $\geq \mathrm{R} 500000$ in the private sector, whereas Roche offers substantially lower prices for Herclon in the public sector. ${ }^{[1]}$ The need for more consistent prices becomes imperative in lieu of the move to introduce universal health coverage in SA.

Finally, it has been suggested that transparency in the pricing of medicines would empower patients to make more informed choices, understand how prices are set and become aware of price discrimination. ${ }^{[10]}$ According to standard economic theory, in most markets, price transparency leads to lower and more uniform prices. Unfortunately, there has been little research conducted to determine if this premise also holds true for the pharmaceutical market.

\section{Conclusion}

SA's medicine pricing interventions are synonymous with an acrimonious history of implementation. Despite government's success in implementing several key polices to reduce medicine prices, considerable more research is required to ascertain if implemented policies have produced the appropriate positive outcomes. Much of the published literature on SA's policy development has covered aspects of the history and a general overview; however, there is a dearth of studies that have looked at policy impact and implication. These studies have become more important as SA moves towards universal healthcare coverage, as this transformation requires integrating the strongest facets of all policies to ensure sustainable access to quality, affordable essential medicines. Transparency in pricing needs to be achieved as well, but to policy makers alone or also to the general public? Does the business model need to be changed for pharmaceuticals? These are questions that the European Union, the USA and even the World Health Organization are currently grappling with.

\section{Acknowledgements. None.}

Author contributions. VB and FS both contributed to the article.

Funding. Research reported in this publication was supported by the Fogarty International Center (FIC), National Institutes of Health (NIH) Common Fund, Office of Strategic Coordination, Office of the Director (CF/OSC/OD/NIH), Office of AIDS Research, Office of the Director (OAR/OD/NIH), National Institute of Mental Health (NIMH/NIH), award number D43TW010131. The content is solely the responsibility of the authors and does not necessarily represent the official views of the NIH.

Conflicts of interest. None.

1. Business Report. \#BadPharma: Pharmaceutical companies behind high cost for cancer medication. 2017. https://www.iol.co.za/business-report/badpharma-pharmaceutical-companies-behind-high2017. https://www.iol.co.za/business-report/badpharma-pharmace
cost-for-cancer-medication-9770177 (accessed 11 December 2017).

2. Carapinha and Company. Single exit price legislation: A source of harm to competition. 2016. http://www.carapinha.com/single-exit-price-legislation-a-source-of-harm-to-competition/\#sthash. XXKTewtG.dpuf (accessed 11 December 2017).

3. Bangalee V, Suleman F. Has the increase in the availability of generic drugs lowered the price of cardiovascular drugs in South Africa? Health SA 2016;21:60-66. https://doi.org/10.1016/j. hsag.2015.10.004

4. Bodhania M. Pharmaceutical sector presentation for private health sector Indaba. 2007. http:// www.slideserve.com/moeshe/pharmaceutical-sector-presentation-for-private-health-sector-indaba (accessed 11 December 2017)

5. Nicolosi E, Gray A. Potential cost savings from generic medicines - protecting the prescribed minimum benefits. S Afr Fam Pract 2009;51(1):59-63.

6. Ngozwana S. Policies to control prices of medicines: Does the South African experience have lessons for other African countries? In: Banda G, Tibandebage P, Wamae W, eds. Making Medicines in Africa. Hampshire, UK: Palgrave Macmillan, 2016:203-223.

Makholwa A. Medicine pricing: New prescriptions needed. 2014. http://ftp.bhfglobal.com/newprescriptions-needed (accessed 14 December 2017)

Hawkins L. Review Series on Pharmaceutical Pricing Policies and Interventions: Working Paper 4: Competition Policy. World Health Organization/Health Action International Project on Medicine Prices and Availability. Geneva: WHO/HAI, 2011

9. Gray A, Suleman F. Pharmaceutical pricing in South Africa. In: Babar Z, ed. Pharmaceutical Prices in the 21st Century. Switzerland: Springer, 2015:251-265.

10. Austin DA, Gravelle JG. Does price transparency improve market efficiency? Implications of empirical evidence in other markets for the health sector. 2007. https://www.fas.org/sgp/crs/misc/RL34101.pdf
evistictions evidence in other markets for
(accessed 11 December 2017).

11. Board of Healthcare Funders of Southern Africa. Health sector inquiry: Pharmaceutical task group's response to third party submissions concerning the pharmaceutical sector. http://www.compcom.
rom.

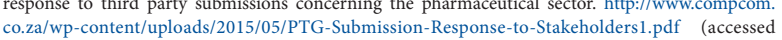
co.za/wp-content/uplo

2. Taylor B. Rationing of medicines and health care technology: Pooling of resources and purchasing of Taylor B. Rationing of medicines and health
health care. S Afr Health Rev 2007;1:123-137.

health care. S Afr Health Rev 2007;1:123-137.
13. Van den Heever A. Review of competition in the South African health system. 2012. http://www. Van den Heever A. Review of competition in the South African health system. 2012. http://www.
compcom.co.za/wp-content/uploads/2014/09/Review-of-Competition-in-the-South-African-Healthcompcom.co.za/wp-content/uploads/2014/09/Review-of-Competition-in-the-South-African-HealthSystem.pdf (accessed 11 December 2017)

14. Daems R, Maes E. Global pharmaceutical management: Building a fair pricing policy (No. 2014/05). 2014. http://web2.msm.nl/RePEc/msm/wpaper/MSM-WP2014-05.pdf (accessed 3 January 2018)

Accepted 18 September 2017 